\title{
Research on the Spatial Pattern of Traditional Villages in Loess Plateau Region
}

\author{
Han Jing \\ College of Urban and Environmental Sciences \\ Northwest University \\ Xi'an710127, China \\ hjxbdx@163.com \\ Wang Xirui \\ College of Urban and Environmental Sciences \\ Northwest University \\ Xi'an710127, China
}

\author{
Ma Teng \\ College of Urban and Environmental Sciences \\ Northwest University \\ Xi’an710127, China \\ Rui Yang \\ College of Urban and Environmental Sciences \\ Northwest University \\ Xi'an710127, China
}

\author{
Zhao Simin* \\ College of Urban and Environmental Sciences \\ Northwest University \\ Xi'an710127, China
}

\begin{abstract}
By application of the methods, such as grid dimension, kernel density estimation, unbalance index and ESDA, the distribution pattern of traditional villages in the Loess Plateau area is comprehensively described from three aspects: spatial agglomeration, spatial differentiation and spatial correlation. The results show that: (1) The distribution of the villages is characterized by "edge density, central sparseness" and the significant inter provincial and intercity. There are 5 agglomeration are as formed on both sides of east and west area. (2) The global and local spatial autocorrelation characteristics of the traditional village distribution are significant. The quantity of cold spot area, sub cold spot area, sub hot spot area and hot spot are are $24,10,9$ and 3 respectively.
\end{abstract}

Keywords-Chinese traditional villages; spatial agglomeration; spatial differentiation; spatial correlation; Loess Plateau area

\section{INTRODUCTION}

With the rapid development of industrialization and urbanization and the violent transformation of rural areas, Chinese traditional villages are suffering from the bad luck of natural extinction and "constructively, tourist and commercial" destruction, so it is imminent to strengthen the protection and utilization of the villages. Since 2012, the Chinese government has successively issued a series of policy documents and standard norms concerning the investigation, assessment, protection and planning of the traditional villages, as well as identified 4 batches, a total of 4153 Chinese traditional villages. With the support of GIS technology, the academic community has used this list to study the spatial distribution of traditional villages and achieved some progress. The results have been

*Sponsor: National Natural Science Foundation of China (No.41601174, No.41601177), Scientific Research Program Funded by Shaanxi Provincial Education Department (Program No.16JK1757, No.16JK1773), The Science Foundation of Northwest University(No.14NW03, No.15NW02)

*Corresponding author: Email: xdzsm@nwu.edu.cn involved in many scales such as nationwide ${ }^{[1-2]}$, economic zone $^{[3]}$, provincial domain ${ }^{[4-5]}$, city domain ${ }^{[6]}$ and so on. Besides the GIS spatial analysis method, the research methods cover $\mathrm{ESDA}^{[1]}$, geographic grid classification ${ }^{[7]}$, geographical detector $^{[3]}$ and so on. But it is also necessary to see that most of the existing studies are based on administrative units but lack of analysis of geographic units. It puts particular emphasis on the discussion of the correlation between the distribution and the geographical elements of the traditional villages, but the overall description of the multi aspects of its spatial pattern is relatively inadequate. Therefore, with the integrity of the natural ecology and the consistency of the cultural landscape, the geographical unit is a preferable measure for the study of the characteristics of the human inhabitation phenomenon. So, based on the example of the Loess Plateau area and by application of the methods, such as grid dimension, nuclear density estimation, unbalance index and ESDA, the characteristics of distribution pattern of traditional villages in the Loess Plateau area is comprehensively described from three aspects: spatial agglomeration, spatial differentiation and spatial correlation, so as to provide ideas for related research.

\section{SURVEY, DATA AND METHODOLOGY}

\section{A. Survey of the research area}

The Loess Plateau is located in the north of central China, including 45 cities and prefectures in 7 provinces, including Qinghai, Gansu, Ningxia, Inner Mongolia, Shaanxi, Shanxi and He'nan, with a total area of $648700 \mathrm{~km}^{2}$. It is a relatively independent topographic unit and has an important position in the development history of the Chinese nation. 


\section{B. Data}

The sample data comes from the four batches of villages listed on the Chinese traditional village list published on the website of the Ministry of Housing and Urban-Rural Development (http://www.mohurd.gov.cn), of which 470 are located in the Loess Plateau (The first batch of 80, the second batch of 52, the third batch of 104, the fourth batch of 234); The terrain data is derived from the digital elevation data of $90 \mathrm{~m}$ resolution provided by the Geospatial Data Gloud (http://www.gscloud.cn). The spatial location information of traditional villages in the Loess Plateau is obtained by using the Baidu map API, and was confirmed by xGeocoding software. ArcGIS10.2 software is applied to visualize the distribution of traditional villages on the topographic map of Loess Plateau (Fig.1).

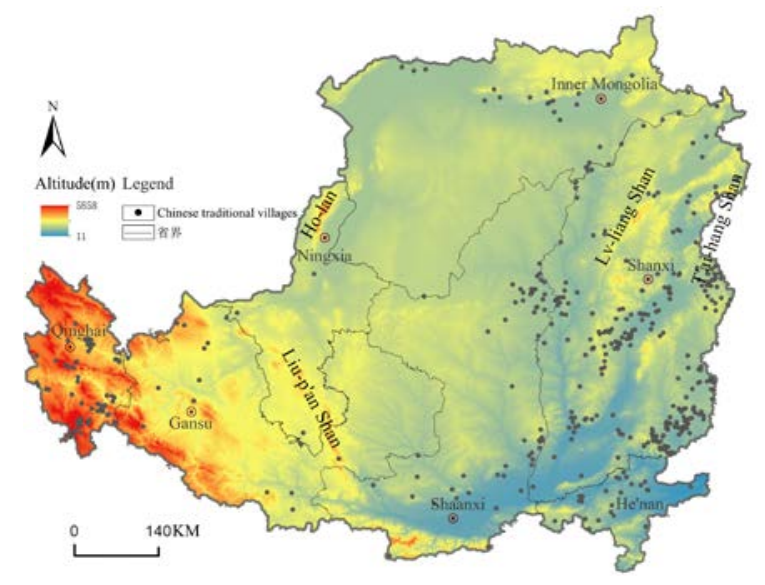

Fig. 1. The distribution of traditional villages in the Loess Plateau

\section{Methodology}

(1) Grid dimension. It is a basic fractal dimension, and it can directly start from the traditional village distribution, depicting its spatial structure characteristics. After the meshing of the research area, it is calculated to draw grid dimension double logarithmic graph and measure the capacity dimension and information dimension. The former can indicate the relationship with the equilibrium and the geographical line of the traditional village distribution. The both difference can further reflect the complex fractal structure of the traditional village system. The calculation formula is detailed in reference literature ${ }^{[8]}$.

(2) Kernel density estimation. It has been widely used in the study of geographical elements distribution, which can directly reflect the spatial agglomeration area of the traditional villages and can be obtained by using the Kernel Density tool in the ArcGIS. The calculation formula is detailed in reference literature $^{[8]}$. In this study, bandwidth has been identified as $100 \mathrm{~km}$ after many tests.

(3) Imbalance index. It can characterize the equilibrium degree of traditional villages in different spatial scales distribution. The calculation formula is detailed in reference literature $^{[4]}$. The index value is $[0,1]$, if $=0$, it indicates that the average distribution of traditional villages in different areas. If
$=1$, it indicates that traditional villages are concentrated in one area.

(4) ESDA. It the spatial correlation measure is taken as the core, and the representative tools include scatter plot and index. The results of the former and the latter can reflect the global and local spatial association characteristics of the traditional villages, respectively. The specific formula is referred to literature $^{[2]}$.

\section{RESULTS AND ANALYSIS}

\section{A. Traditional village spatial agglomeration pattern}

First, the grid dimension was used to detect the distribution of traditional villages. The grid of the research area was segmented by using the fishnet tools in ArcGIS 10.2. The equal value is $[2,10]$. According to the calculation formula of grid dimension, N(r) and I(r) were calculated. Double logarithmic scatter plots were generated by $(\mathrm{N}(\mathrm{r}), \mathrm{K})$ and $(\mathrm{N}(\mathrm{r}), \mathrm{K})$ respectively (Fig.2), and the capacity dimension value and information dimension value were calculated after fitting.
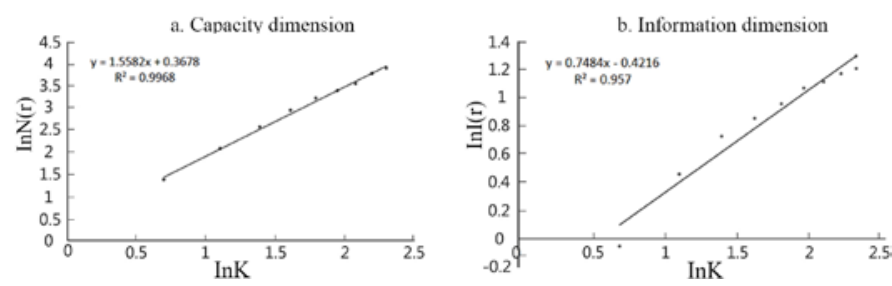

Fig. 2. The Double Logarithmic Scatter Diagram of Grid Dimension of traditional villages in Loess Plateau Area

From Fig. 2, it is seen that there is a significant scale-free interval for the distribution of traditional villages in the Loess Plateau area, and the spatial structure has fractal characteristics. The capacity dimension value is 1.5582 (the coefficient of determination is 0.9968), which is just between 1 and 2 and slightly closer to 2 . It shows that the overall aggregate or discrete pattern of traditional village is not significant, and it is more balanced on the areal scale. The information dimension value is 0.7484 (the coefficient of determination is 0.9570 ), which is significantly less than the capacity dimension value. It shows that the traditional villages have unequal probability distribution in space and the fractal structure is more complex.

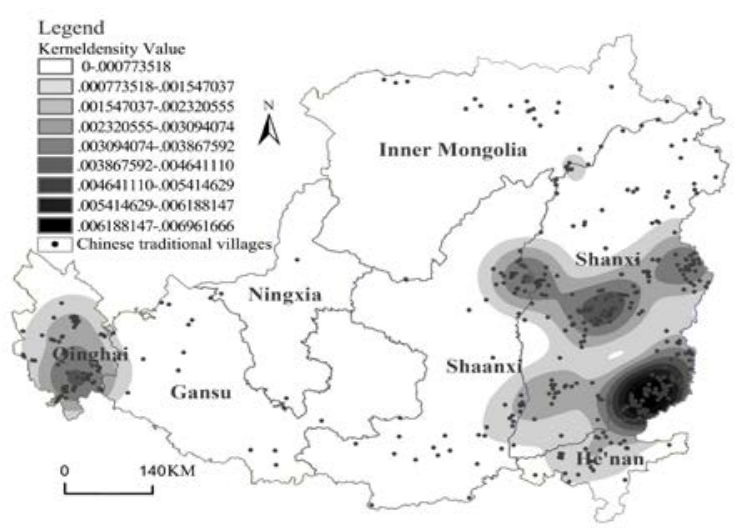

Fig. 3. kernel density map of traditional villages in Loess Plateau Area 
Kernel density mapping for traditional villages is more intuitive to express the spatial structure characteristics (Fig.3). The results show that the distribution of traditional villages in the Loess Plateau area is generally characterized by "edge density ,central sparseness", and 5 distinct aggregation areas have been formed on both sides of the east and west areas. Among them, the traditional village density of Shangdang basin and Zezhou basin in Southeast Shanxi is the highest, and Taiyuan basin, Yangquan basin, Lvliang City, Yulin City along the yellow border area and Xining - Haidong metropolitan area take second place. To sum up, the spatial aggregation characteristics of traditional villages in the Loess Plateau area are highlighted as distribution phenomenons such as "large sparseness and small concentration", "poly basin".

\section{B. The spatial distribution pattern of traditional village}

The number of traditional villages and the proportion of the total area were statisticed by provincial and municipal administrative units(Table 1, table 2). The unbalance index of the provincial and municipal scale are 0.68 and 0.66 respectively, indicating that the distribution of the traditional villages on the Loess Plateau area is unbalance across the two research scales and the provincial difference is more than municipal ones. It's bigger. From table 1, it is seen that the number of traditional villages in Shanxi province has accounted for nearly $60 \%$ of the whole research area, while as the second place, that of two provinces in Qinghai and Shaanxi has accounted for more than $10 \%$. It is known from table 2 that the top five cities of the traditional villages are in Shanxi except for Haidong city, Qinghai Province. The number of eleven municipal traditional villages in the top ten has accounted for $3 / 4$ of the whole research area, while the number of the 5 cities of Ningxia, middle Mongolia, west Mongolia, Ulanqab, Ordos, Wuhai, Dingxi and Linxia in middle Gansu Province, Qingyang, Pingliang in east Gansu Province and Xi'an, Baoji, Tongchuan in the central Shaanxi plain and other 18 municipal traditional villages is below 3 or even empty.

TABLE I. PROVINCIAL ST ATISTICS OF THE DIST RIBUTION OF TRADITIONAL VILLAGES IN THE LOESS PLATEAU AREA

\begin{tabular}{|c|c|c|c|c|}
\hline province & $\begin{array}{c}\text { the number of } \\
\text { traditional } \\
\text { villages } \\
\text { (ones) }\end{array}$ & $\begin{array}{c}\text { proportion } \\
(\mathbf{\%})\end{array}$ & $\begin{array}{c}\text { cumulative } \\
\text { proportion } \\
(\boldsymbol{\%})\end{array}$ & ranking \\
\hline Shangxi & 279 & 59.36 & 59.36 & 1 \\
\hline Qinghai & 68 & 14.47 & 73.83 & 2 \\
\hline Shaanxi & 55 & 11.70 & 85.53 & 3 \\
\hline Henan & 25 & 5.32 & 90.85 & 4 \\
\hline $\begin{array}{c}\text { Inner } \\
\text { Mongolia }\end{array}$ & 23 & 4.89 & 95.74 & 5 \\
\hline Gansu & 15 & 3.19 & 98.93 & 6 \\
\hline Ningxia & 5 & 1.07 & 100 & 7 \\
\hline
\end{tabular}

TABLE II. MUNICIPAL ADMINIST RATIVE UNIT ST ATISTICS OF THE DISTRIBUTION OF TRADITIONAL VILLAGES IN THE LOESS PLATEAU AREA

\begin{tabular}{|c|c|c|c|c|}
\hline $\begin{array}{c}\text { municipal } \\
\text { administrative } \\
\text { unit }\end{array}$ & $\begin{array}{c}\text { the } \\
\text { number of } \\
\text { traditional } \\
\text { villages } \\
\text { (ones) }\end{array}$ & $\begin{array}{c}\text { proportion } \\
(\%)\end{array}$ & $\begin{array}{c}\text { cumulative } \\
\text { proportion } \\
(\%)\end{array}$ & ranking \\
\hline Jincheng City & 69 & 14.68 & 14.68 & 1 \\
\hline
\end{tabular}

\begin{tabular}{|c|c|c|c|c|}
\hline \multicolumn{5}{|c|}{ Cont. to TABLE II } \\
\hline Jinzhong & 50 & 10.64 & 25.32 & 2 \\
\hline Lvliang & 38 & 8.08 & 33.40 & 3 \\
\hline Haidong & 35 & 7.45 & 40.85 & 4 \\
\hline Changzhi & 32 & 6.81 & 47.66 & 5 \\
\hline Yangquan & 24 & 5.11 & 52.77 & 6 \\
\hline Yulin & 24 & 5.11 & 57.88 & 6 \\
\hline Huangnan & 22 & 4.68 & 62.56 & 8 \\
\hline Xinzhou & 20 & 4.26 & 66.82 & 9 \\
\hline Linfen & 19 & 4.04 & 70.86 & 10 \\
\hline Weinan & 19 & 4.04 & 74.90 & 10 \\
\hline Luoyang & 14 & 2.98 & 77.88 & 12 \\
\hline $\begin{array}{l}\text { The City of } \\
\text { SanMenXia }\end{array}$ & 10 & 2.13 & 80.01 & 13 \\
\hline Datong & 10 & 2.13 & 82.14 & 13 \\
\hline Yuncheng & 9 & 1.91 & 84.05 & 15 \\
\hline Baotou & 9 & 1.91 & 85.96 & 15 \\
\hline Xining & 7 & 1.49 & 87.45 & 17 \\
\hline Huhehaote & 6 & 1.28 & 88.73 & 18 \\
\hline Shuozhou & 5 & 1.06 & 89.79 & 19 \\
\hline Hsienyang & 5 & 1.06 & 90.85 & 19 \\
\hline Baiyin & 5 & 1.06 & 91.91 & 19 \\
\hline Lanzhou & 4 & 0.85 & 92.76 & 22 \\
\hline Hainan & 4 & 0.85 & 93.61 & 22 \\
\hline Bayan Nur & 4 & 0.85 & 94.46 & 22 \\
\hline Taiyuan & 3 & 0.64 & 95.10 & 25 \\
\hline Tianshui & 3 & 0.64 & 95.74 & 25 \\
\hline Yan'an & 3 & 0.64 & 96.38 & 25 \\
\hline Xi'an & 2 & 0.43 & 96.81 & 28 \\
\hline Ordos & 2 & 0.43 & 97.24 & 28 \\
\hline Ulanqab & 2 & 0.43 & 97.67 & 28 \\
\hline Guyuan & 2 & 0.43 & 98.10 & 28 \\
\hline Zhongwei & 2 & 0.43 & 98.53 & 28 \\
\hline Wuzhong & 1 & 0.21 & 98.74 & 33 \\
\hline Baoji & 1 & 0.21 & 98.95 & 33 \\
\hline Tongchuan & 1 & 0.21 & 99.16 & 33 \\
\hline Zhengzhou & 1 & 0.21 & 99.37 & 33 \\
\hline Pingliang & 1 & 0.21 & 99.58 & 33 \\
\hline Qingyang & 1 & 0.21 & 99.79 & 33 \\
\hline Linxia & 1 & 0.21 & 100 & 33 \\
\hline Dingxi & 0 & 0 & 100 & 40 \\
\hline Wuhai & 0 & 0 & 100 & 40 \\
\hline Yinchuan & 0 & 0 & 100 & 40 \\
\hline Shizuishan & 0 & 0 & 100 & 40 \\
\hline Haibei & 0 & 0 & 100 & 40 \\
\hline Jiyuan & 0 & 0 & 100 & 40 \\
\hline
\end{tabular}

\section{The spatial association pattern of traditional villages}

The estimated index value, Global Moran's I of spatial distribution of traditional villages in Loess Plateau area is 0.3622 , and the normal statistic value, $z$ is 3.6541 . The index value is positive and is greater 0.01 , and the critical value under the confidence level is 2.576 . Through the significance test, it shows that the distribution of the traditional villages in this area has significant spatial autocorrelation characteristics, and the cities and states with the same number of traditional villages tend to centralize in space. 


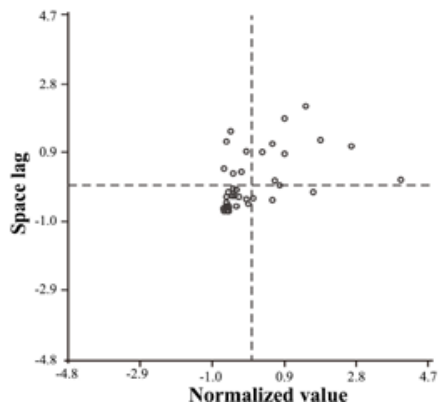

Fig. 4. Scatter plot of Moran

According to the scatter plot of Moran, the city states in the first and the third quadrant are 11 and 24 respectively, accounting for $77.78 \%$ of the total number of the total 45 municipal administrative units. It shows that the local spatial correlation of the distribution of traditional villages in the Loess Plateau area is mainly based on positive correlation. However, the spatial connections between the neighboring cities and towns are mostly expressed as low agglomeration. These three cities,Haidong, Weinan and SanMenXia are the "highland" in the low agglomeration areas, as well as Taiyuan, Yuncheng, Zhengzhou and other 7 cities are "marsh land" in the high agglomeration areas respectively.

Getis-Ord Gi* index was further calculated, and the 45 cities and states were divided into 4 types of areas by using the Jenks Classification Method of Natural Breakpoints in ArcGIS10.2 that generates the hot and cold area figure of the traditional villages in the Loess Plateau area (Fig. 5). From the figure, it is seen that the number of Cold Spot area is the largest, and there are 24; the Sub Cold Sopt area is secondary, and there are 10 , all of which account for more than $3 / 4$ of the total number of cities. Both forms 3 concentrated low agglomeration areas and 2 smaller scale areas are made up of 3 cities and states of Qinghai in the western end of areas and 5 cities along the southeast side of He'nan and Shaanxi along the Yellow River. 1 larger scale area covers all the cities and states in the 3 provinces in Mongolia, Gansu and Ningxia, as well as the 5 cities in Shaanxi and 2 in Northern Shanxi. And the other, Taiyuan belongs to the isolated Cold Spot area. The number of Hot Spots is the least, only 2, that belongs to Jinzhong and Jincheng in Shanxi. There are 9 Sub Hot Spot areas, mainly distributed in Shanxi. It includes 2 cities, such as Yulin, Weinan in Shaanxi, and 2 cities and states, such as Haidong, Huangnan in Qinghai.

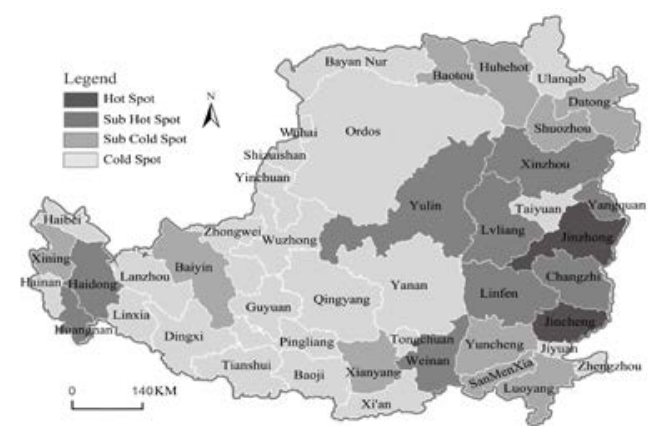

Fig. 5. Hot and cold district map of traditional villages in Loess Plateau Region

\section{Conclusion}

(1) The distribution of traditional villages in the Loess Plateau area presents a pattern of "edge density, sparse central sparseness" and significant inter provincial and municipal differences. Even more, there are 5 agglomeration areas that have been formed on both sides of the east and west area.

(2) The distribution of traditional villages in the Loess Plateau area has both global and local spatial autocorrelation characteristics. The number of cold spot area, sub cold spot area, sub hot spot and hot spot area are 24, 10, 9 and 3 respectively. The spatial connection of neighboring cities and states are more characterized by low agglomeration.

\section{REFERENCES}

[1] KANG J Y, ZHANG J H, HU H, et al. Analysis on the spatial distribution characteristics of Chinese traditional villages[J]. Progress in Geography, 2016, 35(7): 839-850.

[2] LIU D J, HU J, CHEN J Z, et al. The study of spatial distribution pattern of traditional villages in China[J]. China Population, Resources and Environment, 2014, 24(4): 157-162.

[3] GUAN Z M, WANG $\mathrm{T} \mathrm{W}$, ZHI X X. Temporal-spatial pattern differentiation of traditional villages in Central Plains Economic Region[J]. Economic Geography, 2017, 37(9): 225-232.

[4] JIAO S, ZHENG Z M, XU F, et al. The marginal tendency of the traditional village distribution: The case study of Hunan province [J]. Geography Research, 2016, 35(8): 1525-1534.

[5] FENG Y F, YU W Y, LEI R L. Spatial distribution features and controlling factors of traditional villages in Guangdong province [J]. Scientia Geographica Sinica, 2017, 37(2): 236-243.

[6] SUN Y, WANG Y S, XIAO D W, et al. The spatial distribution and evolution of Hakka traditional villages on GIS in Meizhou area [J]. Economic Geography, 2016, 36(10): 193-200.

[7] Yu L, MENG X L. Extracting spatial distribution patterns of the traditional villages based on geographical grid classification method[J]. Progress in Geography, 2016, 35(11): 1388-1396.

[8] RUI Y, TANG B P, WANG X, et al. The spatio-temporal evolutionary characteristics and the impact mechanism of national garden cities in China [J]. Geography Research, 2018, 37(1): 20-36.

[9] GAO C, JIN F J. Spatial pattern and industrial characteristics of economic technological development areas in eastern coastal China [J].Acta Geographica Sinica, 2015, 70(2): 202-213. 